\begin{tabular}{|c|c|c|c|c|c|}
\hline MUNIBE Antropologia-Arkeologia & $\mathrm{n}^{0} 72$ & $57-69$ & DONOSTIA & 2021 & ISSN 1132-2217 • eISSN 2172-4555 \\
\hline
\end{tabular}

\title{
Un enclave singular del Neolítico antiguo en el Prepirineo de Lleida: la Cova del Tabac (Camarasa, Lleida)
}

\author{
A singular early Neolithic site in the Lleida Prepyrenees: \\ Cova del Tabac (Camarasa, Lleida)
}

PALABRAS CLAVES: Cova del Tabac, Aspres de la Noguera, Decoración impreso-incisa, Arte Esquemático. GAKO-HITZAK: Cova del Tabac, Aspres de la Noguera, ebaki bidezko marken dekorazioa, arte eskematikoa. KEY WORDS: Cova del Tabac, Aspres de la Noguera, Imprinted-incised Decoration, Schematic Rock Art.

\section{Susana VEGA BOLIVAR ${ }^{(1,2)}$, Rafael LABORDA LORENTE( ${ }^{(1,3)}$, Paloma LANAU HERNÁEZ ${ }^{(1,3)}$ Xavier RODA GILABERT ${ }^{(1,2)}$, Paloma GONZÁLEZ MARCÉN ${ }^{(1,2)}$ Rafael MORA TORCAL ${ }^{(1,2)}$, Jorge MARTÍNEZ-MORENO ${ }^{(1,2)}$}

\section{RESUMEN}

La Cova del Tabac representa un hito en la Arqueología de la Península Ibérica al combinar la conservación de registro arqueológico y pinturas esquemáticas. No obstante, ha permanecido largo tiempo en el olvido sufriendo múltiples agresiones que dificultan evaluar su significado. Recientes investigaciones han identificado varias fosas amortizadas con artefactos, destacando un conjunto de cerámicas con decoración inciso-impresa adscritas al Neolítico antiguo. La revisión de las figuras del panel al que se añaden nuevas grafías y el hallazgo de cantos con restos de ocre, incrementan el interés de este enclave.

La posición cronométrica del registro material, 5300-5000 cal BC, visibiliza un nuevo evento Neolítico que se rastrea por el Prepirineo Oriental compatible con el rango temporal de las pinturas esquemáticas. Cova del Tabac permite evaluar la irrupción de este fenómeno en los Aspres de la Noguera a finales del VI Milenio BC.

\section{LABURPENA}

Cova del Tabac haitzuloak Iberiar penintsulako arkeologian mugarri modukoa osatzen duela esan dezakegu; izan ere, erregistro arkeologikoa eta pintura eskematikoak bateratzen ditu. Dena den, denbora luzez ahaztuta egon da eta esanahia ebaluatzea zailtzen duten eraso ugari jasan ditu. Azken urteotan egindako ikerketek amortizatutako hainbat hobi identifikatu dute objektuekin eta, horien artean, antzinako Neolitoko ebaki bidezko marken dekorazioa duten zeramiken multzoa nabarmendu behar dugu. Toki honen interesa areagotu egin dute okre-hondarrak dituzten harri-koskorrak topatu izanak eta grafia berriak gehitu zaizkien paneleko figuretan egindako berrikusketak.

Erregistro materialaren posizio kronometrikoak (K.a. 5300-5000, gutxi gorabehera) Neolito garaiko gertakari berri bat erakutsi du. Mendebaldeko Pirineoaurrekoan egin da horren jarraipena eta pintura eskematikoen denbora mailako tartearekin bateragarria da. Cova del Tabaci esker, fenomenoak K.a.VI. Milurtekoaren amaieran Aspres de la Nogueran izan zuen sarrera ebaluatzea ahalbidetu digu.

\section{ABSTRACT}

Cova del Tabac in the eastern Catalan Prepyrenees, can be considered a milestone in the history of the Iberian archaeology. The settlement was discovered at the end of the $19^{\text {th }}$ century, and later in the 80 s of the $20^{\text {th }}$ century was identified an enigmatic panel with Schematic art. The combination of archaeological record and rock art composes an interesting singularity, defining this singular enclave. Despite, this it has been abandoned and systematically plundered until today. Recent excavation in a poorly lit area $35 \mathrm{~m}$ from the entrance of the cave, a hearth and several pits with archaeological materials were detected. Among the findings stands out a set of ceramics with imprinted-incised decoration attributed to the early Neolithic, which it has been dated between 5300-5000 cal BC. Although very altered, the cave preserves a panel with schematic representations with a strong symbolic meaning, such as anthropomorphic and sun-shaped depictions. New signs have been identified in an adjacent area, among others a double "Y"-shaped anthropomorphic sign, confirming the relevance of these symbolic expressions with formal similarities with those recorded throughout the Schematic Rock Art. The discovery of cobbles with use wear traces and mineral residues suggests possible links with the paintings.

Cova del Tabac visualizes the incipient neolithization of the Prepyrenees, an independent event which took place slightly later than the Cardial development. This event is closely linked to the consolidation of this organizational system in northern Iberia, seems deeply rooted in the area of Aspres de la Noguera. The possible correspondence between the material assemblage and the art manifestations inside the cave, allow proposing that the Cova del Tabac could play a unique role in the development of this area during the last third of the VIth millennium BC.

\footnotetext{
(1) Centre d'Estudis del Patrimoni Arqueològic-CEPARQ. Universitat Autònoma de Barcelona, 08193 Bellaterra, Spain.

(2) Associació Recerca i Difusió del Patrimoni Històric Centro I+D, C/Major 11, 25613 St. Llorenç de Montgai, Spain.

(3) Departamento de Ciencias de la Antigüedad Pedro Cerbuna 12, 50009 Zaragoza, Spain.
} 


\section{LA ATRIBULADA HISTORIA DE LA COVA DEL TABAC}

Diversas circunstancias erigen la Cova del Tabac (Camarasa, Lleida) en un enclave singular. Su descubrimiento por Lluis M. Vidal (1894) junto al imprescindible catálogo de materiales elaborado por Josep Serra-Ràfols (1921) se convirtieron en un referente para el desarrollo de la Arqueología en Catalunya a principios del siglo XX. Otro elemento destacado es la primera descripción del conjunto de arte Esquemático realizada por Luis Díez Coronel (1985) y su declaración ese año como Bé Cultural de Interès Nacional (PH BCIN 2049-ZA), figura de máxima protección patrimonial otorgada por el Departament de Cultura de la Generalitat de Catalunya. Paralelamente, este conjunto se publica formalmente dentro del Corpus d'Art Rupestre de Catalunya (Castells (dir.), 1990), y en 1998 se integra en la Declaración del Patrimonio Mundial del Arte Rupestre del Arco Mediterráneo de la Península Ibérica promovida por la UNESCO. Pese a estos antecedes esta cavidad ha sufrido un absoluto abandono y expolio, evidente en las irreversibles agresiones sufridas por las pinturas rupestres.

Con el objetivo de paliar esta situación, en 2017 el Servei d'Arqueologia i Paleontologia de la Generalitat de Catalunya y el Ajuntament de Camarasa (Lleida) procedieron a limpiar y estabilizar las pinturas, implementando medidas dirigidas a regular la visita a un espacio muy frecuentado por excursionistas. En 2018, el CEPARQ-UAB inicia un proyecto que combina distintas acciones orientadas a preservar los componentes naturales y culturales de este entorno. Los resultados de estas medidas deberán concretarse en los próximos años (Vega et al., 2020).
Los trabajos de excavación iniciados en 2019 permitieron recuperar un conjunto de artefactos con contexto preciso que se adscriben al Neolítico antiguo, situación que contrasta con los escasos restos conocidos actualmente diseminados por varios fondos de museos de Catalunya (Oms, 2014). Paralelamente, la revisión del conjunto esquemático y el hallazgo de nuevas grafías renuevan el interés por este clásico, pero desconocido, yacimiento.

\section{LA COVA DEL TABAC COMO ESPACIO SINGULAR}

El espacio geográfico en el que se ubica la cavidad no es un recurso descriptivo, es un atributo definitorio de este enclave. A escasos kilómetros aguas abajo de la confluencia con el Noguera Pallaresa, el cauce del río Segre transcurre por una imponente garganta al pie de desplomados de más 300 m que se resiguen varios kilómetros, entre las sierras Carbonera y el Mont Roig. Este paisaje icónico de los Aspres de la Noguera advierte del radical contraste biogeográfico a resultas del abrupto cabalgamiento de las primeras estribaciones del Prepirineo de Lleida sobre la llanura de la Depresión del Ebro (Mora et al., 2019) (Fig. 1).

En la parte superior de los escarpes del Mont Roig a $630 \mathrm{~m}$ y visible por todo el valle se localiza la Cova del Tabac (UTM X: 324032; UTM Y: 4641052 (ETRS89). Actualmente, su acceso se realiza bordeando la montaña a través una pista forestal que partiendo del pantano de Camarasa sigue un accidentado itinerario con tramos que se superan con la ayuda de cadenas y grapas. No es fácil evaluar posibles rutas empleadas en el pasado, aunque parece poco probable la ascensión directa atacando la cara en la que se expone la cueva.
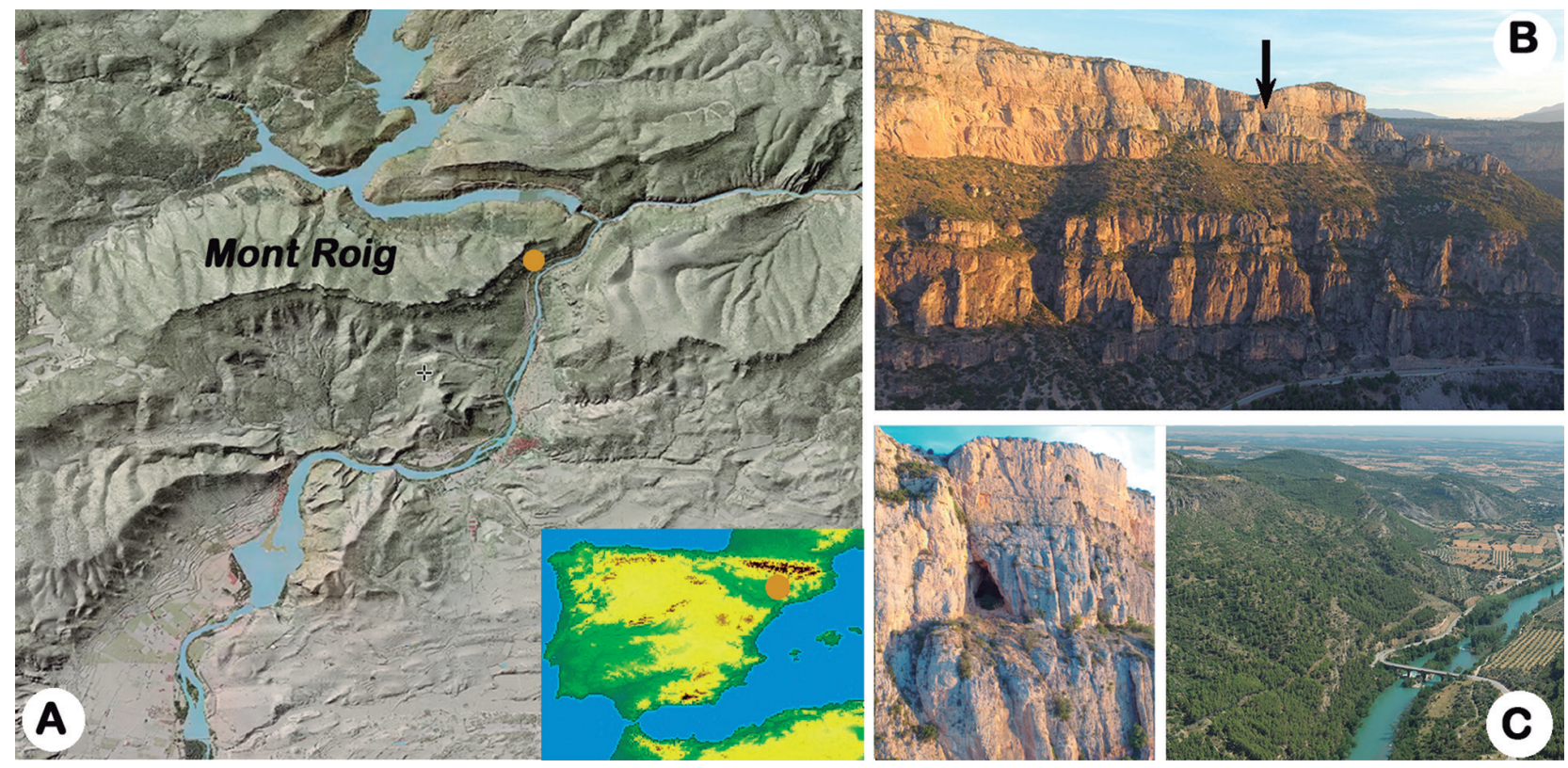

Fig.1. Cova del Tabac. A) Localización del Mont Roig en la confluencia de los ríos Noguera Pallaresa y el Segre. B) Posición de la cueva en la parte superior del desfiladero. C) Vista del acceso a la cavidad y del valle del Segre desde la cueva. / Cova del Tabac. A) Location of the Mont Roig. B) Position of the cave on the gorge. C) View of the cave entrance and the Segre valley from the cave. 
El sistema cárstico tiene un desarrollo horizontal de $300 \mathrm{~m}$ al que se accede por un gran pórtico (17×15 m) en el que aboca un talud de $15 \mathrm{~m}$ que lo conecta con una amplia sala elipsoidal de $25 \times 25 \mathrm{~m}$. La insolación de este espacio se atenúa a medida que se avanza hacia el interior de la sala, punto en el que el karst cambia de dirección requiriendo luz artificial para circular por el resto de la cavidad. Este recorrido es obstruido por una brecha que tapona la conexión con la Cova del Pas del Sastre, que originariamente formaría una única galería que atravesaba el Mont Roig (Fig. 2).

\section{PRIMEROS RESULTADOS DE LOS TRABAJOS ARQUEOLÓGICOS}

En la cueva se han sucedido numerosas intervenciones incontroladas de las que se dispone de escasa información. Ocasionalmente en boletines de excursionistas se menciona la recogida de materiales, en otros casos se sospecha de excavaciones con un impacto desconocido (de la Vega, 1981). Estos antecedentes hacían suponer que la cavidad estaba saqueada, como ocurre con muchas cuevas con registro arqueológico del Prepirineo de Lleida (Oms, 2014).

Al iniciar la excavación se consideró sondear una zona que conservaba sedimento en el lateral izquierdo de la sala elipsoidal, a 35 metros del pórtico y adyacente al dintel que divide la parte externa e interna de la cueva, en el que se posicionan las pinturas rupestres (Fig. 2A). Un sondeo de 3x3 m identificó un primer estrato compuesto por tierras movilizadas sin llegar a determinar cuándo se realizó ese expolio, o si afectó a niveles arqueológicos (Fig. 2B).

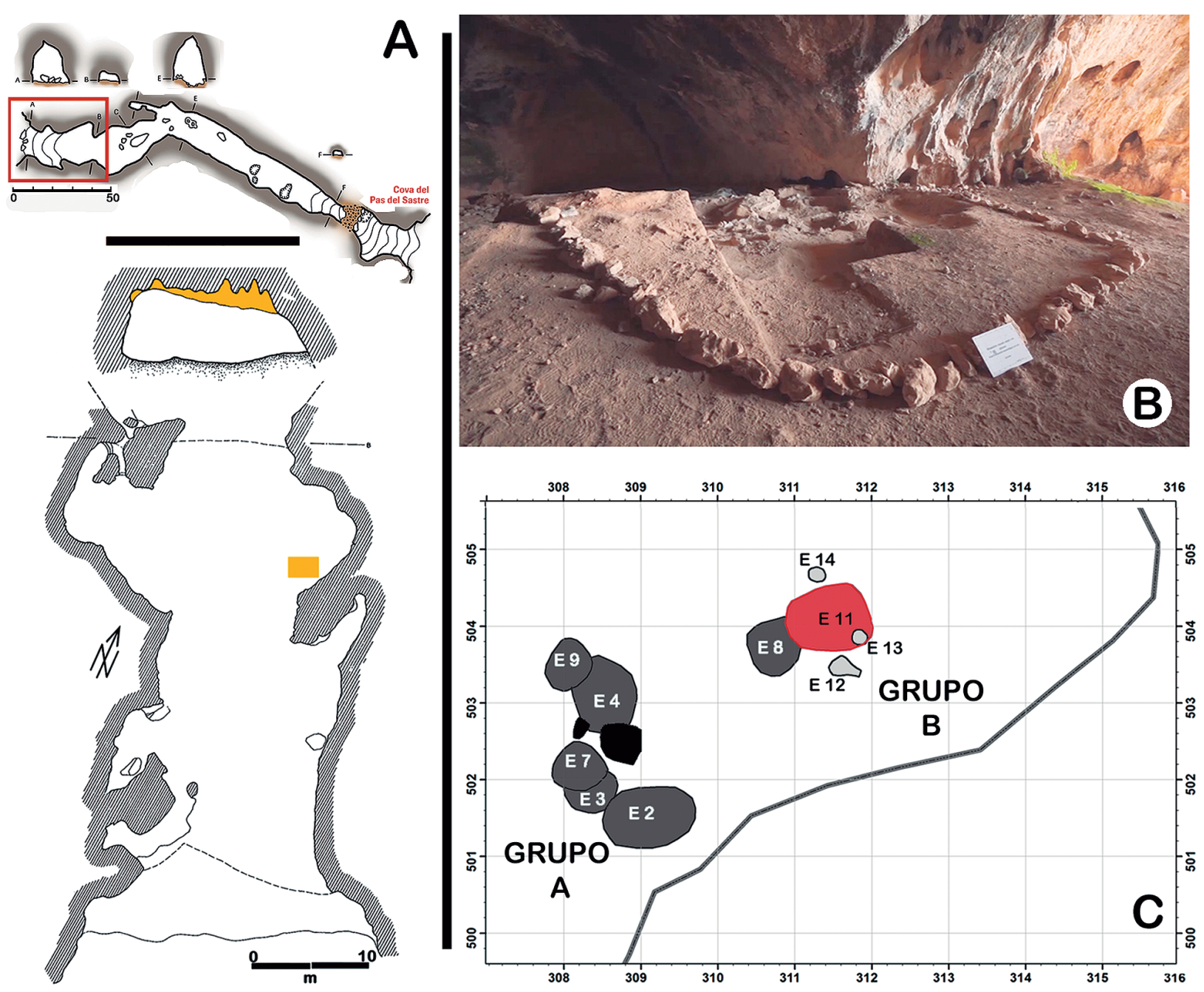

Fig.2. A) Planta del sistema kárstico de la Cova Tabac. En la parte inferior se señala la entrada y la sala elipsoidal posicionando la zona de excavación y en la parte superior el dintel donde aparecen las pinturas (en amarillo) (modificado a partir de Castells (dir), 1990). B) Vista de la zona excavada. C) Grupos A y B: se indica la superposición de las fosas E 9/ E 4 y E 7/E 3 (gris oscuro), el hogar E 11 (rojo) instalado sobre E 8 , y 3 pequeñas depresiones (gris claro). ( A) Plan of the Cova Tabac. In the bottom, the entrance and the ellipsoidal room with the position of the excavated area and the walk with paintings (yellow) (modified from Castells (dir), 1990). B) Excavated area. C) Plan with groups A and B, indicating the overlapping between pits (gray) and the hearth E 11 (red) covering E 8, and 3 small pits (gray clear). 
Por debajo de esta remoción se reconocieron varias estructuras prehistóricas denominadas grupo A y grupo B. El grupo A integra 5 fosas, tres con un eje máximo de $0,5 \mathrm{~m}$ (E9, E7, E3) y dos de $1 \mathrm{~m}$ (E4 y E2), y hasta $0,5 \mathrm{~m}$ de potencia. Algunas de ellas están cortadas entre sí (Fig. 2C). El material aparece desorganizado sin que se identifiquen distintas fases de colmatación dentro de los contendores lo que sugiere una rápida amortización, posiblemente en eventos únicos que se suceden en una escala temporal breve. Al expandir la excavación, a 2,5 m de distancia se detectó el conjunto B, compuesto por una fosa similar a las anteriores (E8), parcialmente cubierta por un hogar de $1 \mathrm{~m}$ de longitud (E11) que anexaba 3 pequeñas depresiones, de entre $15-20 \mathrm{~cm}$ de diámetro, una de ellas sólo contenía un canto tintado de ocre (E12) (Fig. 2C). La imbricación entre fosas de acumulación de residuos y posibles agujeros de poste relacionados con el hogar advierte de un espacio que focaliza diversas actividades. En cuevas próximas se ha señalado la ubicación redundante de estructuras atribuidas a distintas fases cronoculturales (Oms et al., 2013), pero en la Cova del Tabac se desconocían este tipo de contextos arqueológicos.

\section{EL CONTEXTO RADIOMÉTRICO}

Una cuestión prioritaria pasaba por disponer de una serie de fechas que conformaran un registro cronométrico representativo del conjunto. 4 dataciones por ${ }^{14} \mathrm{C}$ AMS obtenidas sobre muestras de vida corta derivan rangos temporales para los que se puede asumir una estrecha relación entre fecha y contexto. Los resultados fueron tratados con OxCal v 4.4.2 (Bronk Ramsey, 2020) y se expresan como intervalos calibrados $2 \partial$, definiendo una serie radiométrica precisa y homogénea (Tabla 1). La fecha más antigua corresponde con la fosa E8, entre 5300-5200 cal BC, es ligeramente anterior a la del hogar E11 lo que concuerda con la superposición observada entre estas estructuras. Las fechas de E11, E4 y E9, entre 5200-5000 cal BC, señalan que E9 es ligeramente anterior a E4, coherente con lo documentado durante su excavación al identificarse que E9 cortaba a E4 (Fig. 3).

La serie señala una sucesión de eventos que se interpolan en un rango temporal relativamente breve y sugiere que algunas de estas estructuras pudieron ser sincrónicas, cuestión que podrá evaluarse a partir del remontaje de materiales entre fosas. Esta franja temporal, que deberá examinarse en función de futuros resultados radiométricos, se posiciona dentro del tercio final del VI Milenio cal BC.

\section{CARACTERIZACIÓN PRELIMINAR DEL REGIS- TRO MATERIAL}

En el transcurso de estos trabajos se recuperó una significativa asociación de artefactos y ecofactos, actualmente en estudio y que subrayan la importancia de

\begin{tabular}{|c|c|c|c|c|c|c|c|c|}
\hline \# LAB. & GRUPO & CONTEXTO & MUESTRA & BP & $\partial$ & ${ }^{213} \mathrm{C}$ & \multicolumn{2}{|c|}{ Cal BC (2d) } \\
\hline Beta 547043 & B & E8-2029 & T. dicoccum & 6230 & 30 & $-23,5$ & -5302 & -5070 \\
\hline Beta 547041 & $B$ & E11-2025 & T. aestivum/durum & 6150 & 30 & $-23,3$ & -5210 & -5009 \\
\hline Beta 547042 & $A$ & E9-2027 & Corylus & 6190 & 30 & $-25,2$ & -5227 & -5041 \\
\hline Beta 547040 & $A$ & E4-2023 & T. Aestivum/durum & 6140 & 30 & $-24,4$ & -5209 & -5002 \\
\hline
\end{tabular}

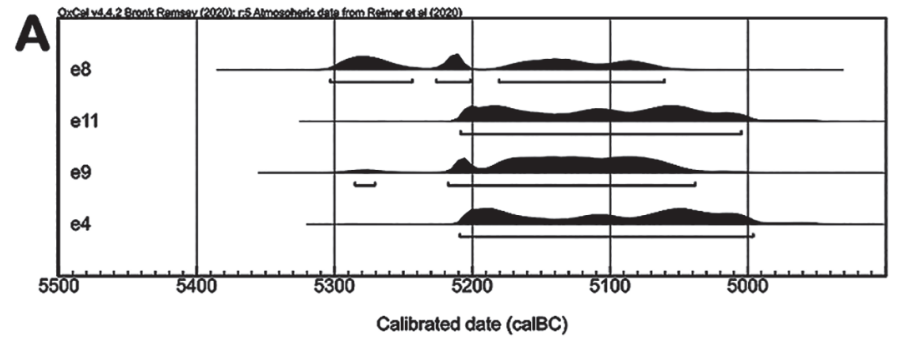

B

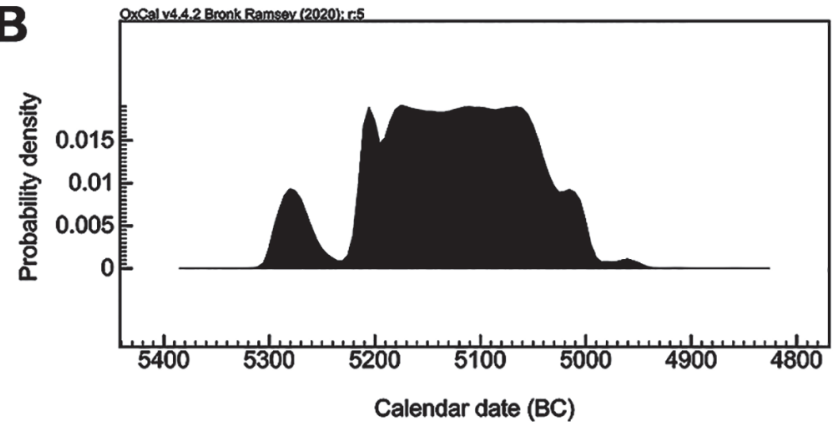

Tabla 1: Serie ${ }^{14} \mathrm{C}$. Las fechas $\mathrm{BP}$ fueron calibradas a $2 \mathrm{\partial}$ con OxCal v4.4.2 (Bronk Ramsey 2020). La determinación taxonómica de las muestras fue realizada por la Dra. Natalia Alonso (Univ, de Lleida). / Series ${ }^{14} \mathrm{C}$. BP dates calibrated to $2 \partial$ with OxCal v4.4.2. (Bronk Ramsey 2020). Taxonomical samples determination was performed by Dra. Natalia Alonso (Univ. de Lleida).
Fig.3. A) Representación gráfica de las fechas ${ }^{14} \mathrm{C}$; B) acumulación de probabilidades de la serie radiométrica. Gráficos generados por Oxcal v4.4.2. (Bronk Ramsey 2020). / A) Graph of ${ }^{14} \mathrm{C}$ dates; B) accumulation of probabilities of the series. Graphics generated by Oxcal v4.4.2. (Bronk Ramsey 2020). 
este sitio. En la evaluación de estos materiales son pertinentes las observaciones de LI. M. Vidal (1894) y el catálogo elaborado por J. Serra-Ràfols (1921) que confirman la coherencia entre esta colección y el conjunto recuperado en la excavación, ampliando el registro de materiales de la Cova del Tabac.

\subsection{El conjunto cerámico}

Los atributos tecno-morfológicos y decorativos del conjunto cerámico señalan un mínimo de 47 vasos decorados pero debido a su alta fragmentación la mayoría se identifican a partir de un único resto. La ausencia de erosiones o rodamientos en las fracturas indica una buena conservación y sugiere una rápida deposición en las fosas. El conjunto se compone de 8 recipientes grandes, 19 medianos, 10 pequeños y 10 indeterminados. Destacan dos bastante completos: una vasija de $>25 \mathrm{~cm}$ de diámetro de boca (vaso 1) y una botella de grandes dimensiones con $12,5 \mathrm{~cm}$ de diámetro de boca (vaso 21). El resto remiten a formas abiertas como cuencos hemisféricos y vasijas ovoides de perfil recto, formas cerradas asimilables a recipientes globulares o vasijas ovoides de perfil cerrado, y formas con cuello destacado y/o botellas (Fig. 4). Las diferencias cromáticas de sus superficies indican cocciones irregulares sobre hoguera en las que dominan las cocciones reductoras frente a las oxidantes. Los acabados están muy cuidados siendo habituales las superficies bruñidas, espatuladas y alisadas. Las escasas superficies erosionadas avalan la buena conservación del conjunto.

Diferentes tipos de impresiones conforman la mitad de las decoraciones que se han diferenciado en función del número de puntas del instrumento, digitaciones y/o ungulaciones presentes en estos motivos incisos e inciso-impresos (Tabla 2). En varios vasos se realizan impresiones oblicuas sobre la pasta fresca para abultar el espesor de las paredes. Es común la aplicación de cordones lisos o impresos. Se recuperaron 2 restos con boquique que se suman a los conocidos en las colecciones antiguas, mostrando como suele ser habitual en esta zona que la presencia de esta técnica es muy limitada (Oms, 2014; Laborda, 2019). Serra-Ràfols (1921) señaló semejanzas entre estos motivos con las decoraciones de las cerámicas de la cueva de Boquique. Hasta el momento no ha aparecido cerámica impresa cardial.
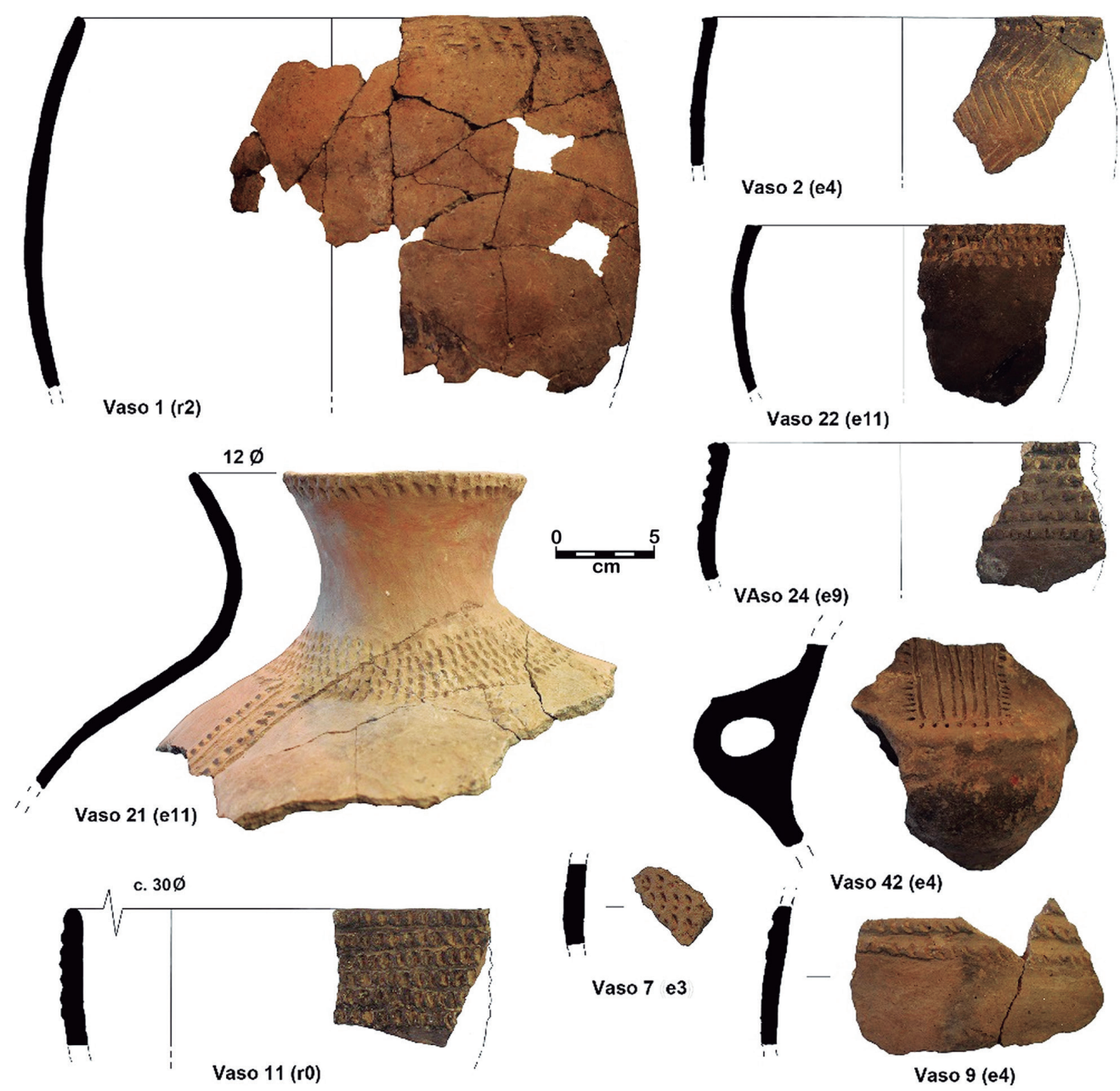

Fig.4. Conjunto cerámico con decoraciones impreso-incisas y cordones atribuidas al Neolítico antiguo. Se indican la vasija (vaso 1) y botella (vaso 21). / Early Neolithic Imprinted-incised ceramics. The vessel (1) and bottle (21) are indicated. 


\begin{tabular}{|l|l|l|}
\hline Técnicas decorativas & $\mathbf{N}$ & $\%$ \\
\hline Impresión instrumento & 14 & 29,8 \\
\hline Impresión ungulación/digitación & 5 & 10,6 \\
\hline Impresión doble & 4 & 8,5 \\
\hline Total Impresión & $\mathbf{2 3}$ & $\mathbf{4 8 , 9}$ \\
\hline Boquique & 2 & 4,3 \\
\hline Cordón liso & 7 & 14,9 \\
\hline Cordón impreso & 7 & 14,9 \\
\hline Incisión & 3 & 6,4 \\
\hline Incisión-impresa & 4 & 8,5 \\
\hline Labio con pezones & 1 & 2,1 \\
\hline Total & $\mathbf{4 7}$ & $\mathbf{1 0 0}$ \\
\hline
\end{tabular}

Tabla 2: Desglose de técnicas decorativas del conjunto cerámico a partir de fragmentos decorados. / Decorative techniques of the ceramic assemblage from decorated fragments.

La práctica totalidad de decoraciones definen motivos sencillos y en la parte superior de 42 fragmentos se aplican bandas horizontales de grosor variable. Son habituales uno o varios cordones horizontales lisos o impresos. 3 vasos presentan motivos complejos: un caso son bandas paralelas limitadas por impresiones, otro serían meandros descendentes, y varios motivos que se combinan en la botella. La asociación de motivos impresos, acanalados, inciso-impresos, cordones, boquique remite a la esfera de las decoraciones impreso-incisas, tradicionalmente referido como Epicardial. La actual revisión del significado de este horizonte cronocultural nos lleva a proponer la denominación de Neolítico antiguo para identificar este evento que se registra entre las cuencas del Cinca-Segre del Prepirineo y en el interior de Iberia (Oms, 2014; Rojo et al., 2018; Laborda, 2019), cuya extensión corológica por els Aspres de la Noguera se discute más adelante (ver apartado 7.3).

\subsection{Artefactos tallados e instrumental sobre canto}

El conjunto tallado se elabora principalmente a partir de la variedad de sílex negro que asignamos a los afloramientos de la Serra Llarga integrados en la Formación Castelltallat a 30 km de distancia (Roy et al., 2013; Ortega et al. 2018) (Fig. 8), determinación que deberá verificarse ya que litologías similares aparecen en los Monegros a más $90 \mathrm{~km}$. En menor medida, algunos restos líticos de sílex Garumniense remiten a un entorno local (Roy et al., 2013). El instrumental lítico se obtiene por un método de talla que genera soportes repetitivos y alargados, con caras dorsales con aristas paralelas y perfil curvo. Los puntos de impacto indican la aplicación de percusión lanzada indirecta que permite extraer series de láminas y laminitas normalizadas, sistemática común durante el Neolítico (Binder et al., 1990). Dominan los soportes con filos brutos, frente a las piezas retocadas. Serra-Rafols, (1921) ejemplifica varias de las "hojas" de sílex recogidas por Vidal.

El segundo componente son 76 cantos habitualmente fragmentados. Sus patrones morfométricos corresponden con volúmenes esféricos de entre 15-20

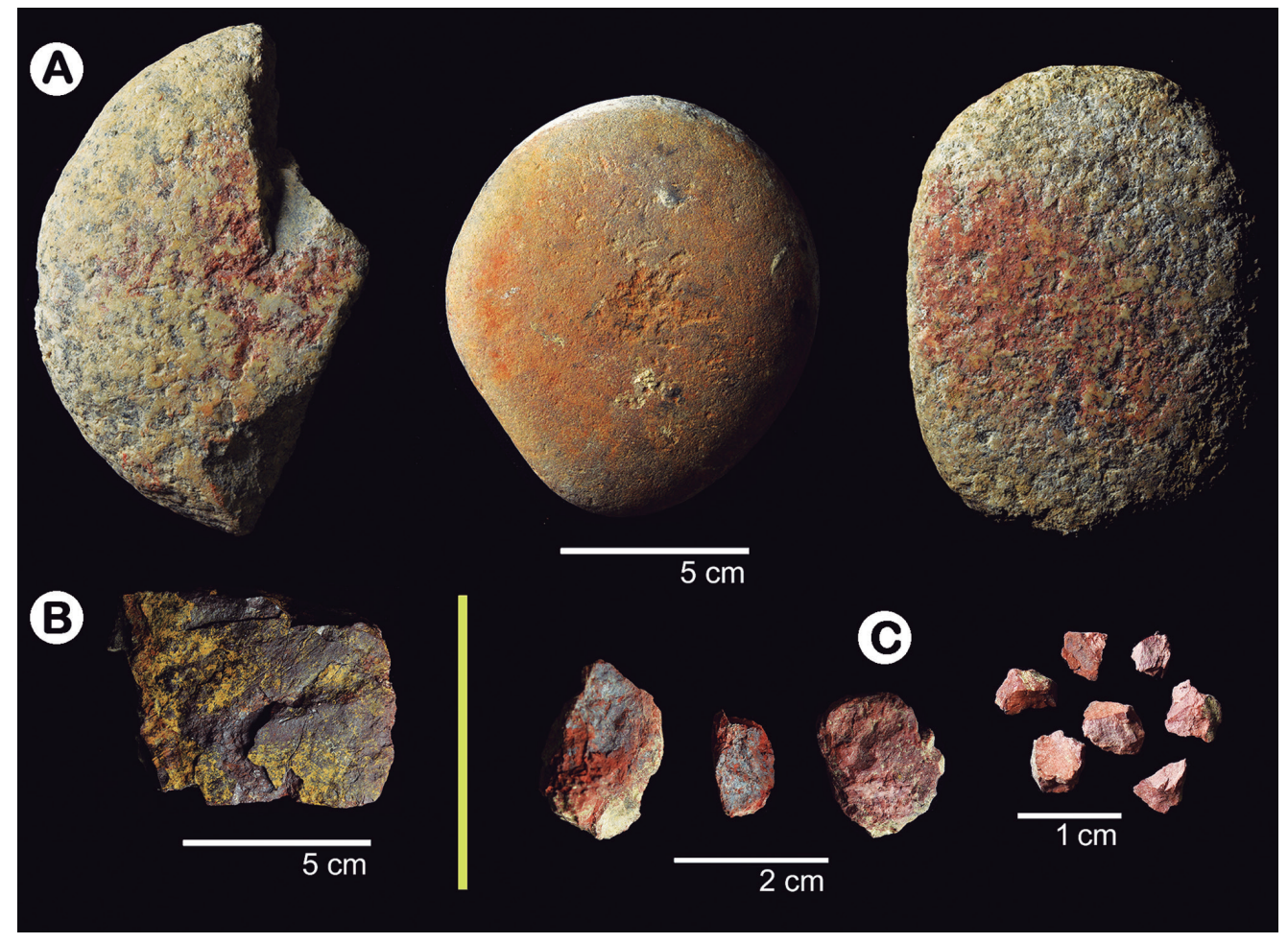

Fig.5. Indicadores relacionados con la preparación de pigmentos: a) cantos empleados en el machacado y molienda de minerales con residuos adheridos de ocre; b) bloque de oligisto con huellas de percusión; c) residuos de mineral rojo derivados del procesado de pigmentos. / A) cobbles used in crushing and grinding of $\mathrm{mi}-$ nerals with adhered ocher; b) Oligist iron block with percussion marks; c) crushed mineral fragments. 
cm de tamaño. Las litologías más habituales son la caliza, cuarcita y granito y, en menor medida arenisca y cuarzo, presentes en el entorno fluvial adyacente (Roy et al., 2017). Aunque el significado funcional de estos artefactos está en estudio, se identifican zonas activas con huellas de percusión lanzada que configuran depresiones centralizadas (cazoletas), y estigmas ligados a la percusión amortiguada como abrasiones, fricciones perimetrales o estrías características del instrumental pulimentado. Algunos preservan rastros de pigmentos que indican su uso para machacar y pulverizar rocas de mineral rojo (Roda et al. 2016) que coincide con la recuperación en la excavación de numerosos fragmentos y residuos (Fig. 5). Vidal recuperó varios molinos y percutores con residuos de ocre, que vinculó con la molienda de minerales citando uno con residuos de oligisto y un mortero de grandes dimensiones con una cúpula central bien formateada (Serra-Ràfols, 1921). Varios pilones rotos (uno con pigmentos) refieren a esta actividad.

\subsection{Elementos de ornamento}

Dentro la esfera ornamental se recuperaron artefactos sobre concha y sobre piedra (Fig. 6). Se han recuperado dos Theodoxus fluviatilis perforados, uno de ellos quemado y 2 fragmentos de brazalete de Glycymeris glycymeris que corresponden con la mitad del perímetro, sin poder precisarse si corresponden con piezas completas rotas o articulaban con otros. Uno compuesto por 3 trozos que no remontan, apareció quemado en el hogar E11. Serra Ràfols (1921) documenta un fragmento de brazalete y una valva de Glycymeris. Entre los adornos de piedra destaca un soporte rectangular ligeramente curvo y base seccionada, fracturado a nivel de la perforación. Aunque la cortical de una cara se desprendió posiblemente por exposición al fuego, el artefacto está intensamente pulido. Un segundo grupo son 15 cuentas discoidales de diversa litología, y una cuenta elipsoidal grande y espesa con perforación central. Finalmente, 5 gravillas de sedimento de $1 \mathrm{~cm}$ intencionalmente perforadas y sin aparente significado funcional, pudieron formar parte del conjunto ornamental. Serra-Ráfols (1921) señala un pequeño colgante cuadrangular con perforación semioval.

\subsection{Los restos óseos}

La fauna asignada a mamíferos de talla grande y media está bien conservada, y aunque su estudio está en curso se pueden realizar varias observaciones. Se identifican caprinos (Ovis aries/Capra hircus) y bovinos (Bos taurus) domésticos, pero a falta de datos cuantitativos parece que, la especie más abundante es el ciervo (Cervus elaphus), tal y como advirtió Vidal. Los restos de suidos son escasos y se atribuyen a Sus scrofa, mieentras la presencia de la forma doméstica no es segura. Los restos de Canis sp. pueden corresponder a un animal doméstico. Otras especies identificadas a partir de restos únicos son un núcleo óseo de Capra pyrenaica, y una falange de Equus ferus que expande la distribución de esta especie por el Prepirineo (Altuna y Mariezkurrena, 2009). Como carnívoros cabe citar el tejón (Meles meles) y el lince (Lynx sp.). Los lagomorfos (Oryctolagus cunniculus) no son abundantes dentro del conjunto.

La escasa presencia de microfauna (roedores, aves, anfibios o quirópteros) no es un sesgo de exca-

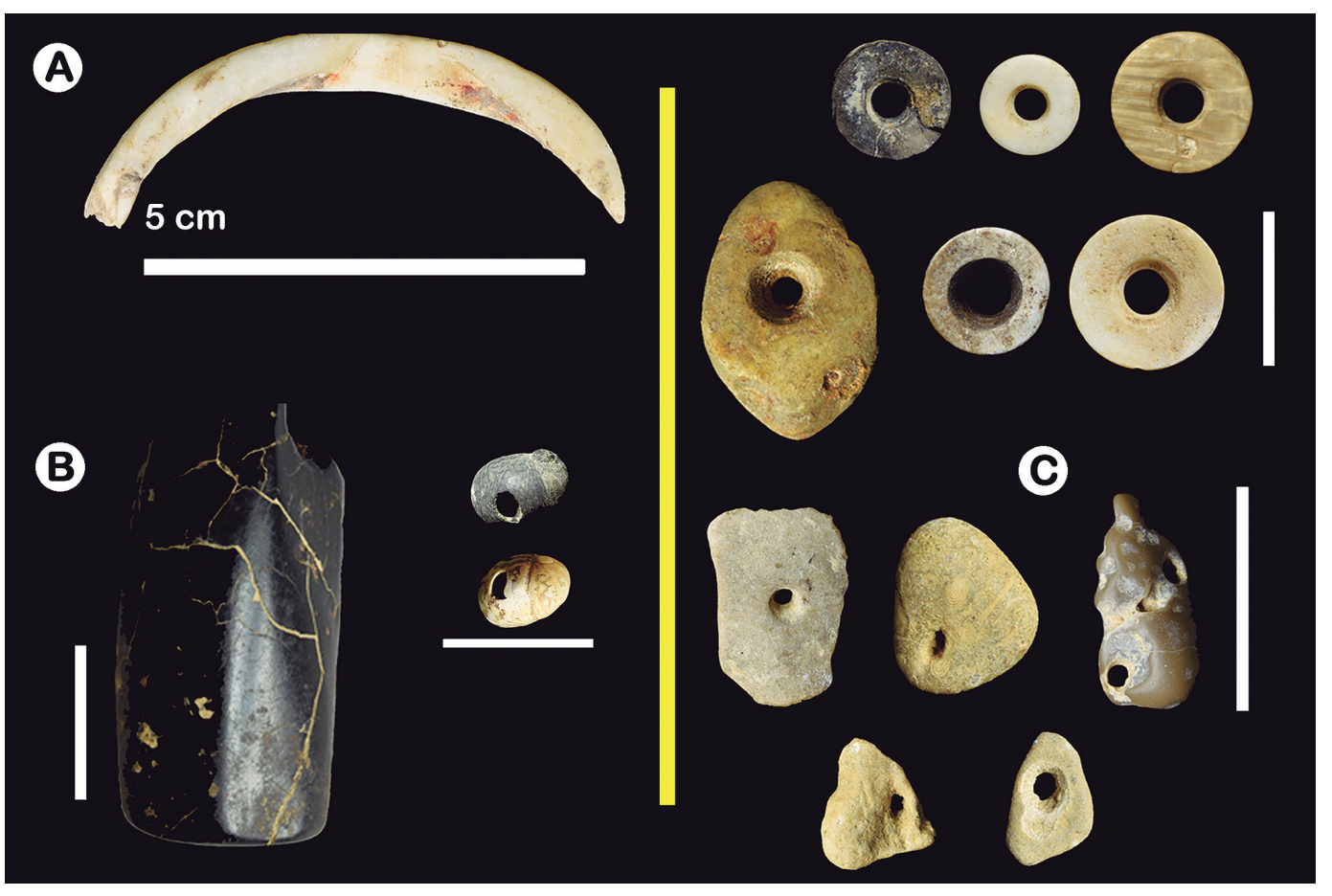

Fig.6. Ornamentos. A) Fragmento de brazalete de Glycymeris, B) colgante curvo de piedra y Theodoxus fluviatilis perforados. C) Diferentes tipos de cuentas: elipsoidal, discoideas. En la parte inferior gravillas perforadas. Escala gráfica $1 \mathrm{~cm}$, excepto el brazalete.. / Ornaments. A) Glycymeris bracelet fragment, B) curved pendant and Theodoxus fluviatilis. C) Elipsoidal and discoidal beads. Bottom perforated fine gravels. Graphic scale $1 \mathrm{~cm}$, except the bracelet. 
vación ya que el sedimento fue cribado con agua. Alternativamente podría indicar que estos contenedores no restan abiertos de forma prolongada, o que esta zona de la cueva no parece idónea para la instalación de agentes acumuladores diurnos o nocturnos.

Paralelamente, 5 restos se transformaron en artefactos. Así, un fragmento troncocónico de sección circular quemado conforma un apuntado roto por ambos extremos. Una diáfisis de mamífero de talla grande sirve de soporte para elaborar un apuntado. En un extremo de una diáfisis rectangular de un mamífero grande convergen marcas de fricción y pulido delineando una zona activa asociada a un brillo que indica un área activa relacionada con una actividad no determinada. Dos fragmentos apicales de soportes apuntados presentan fracturas de uso.

\section{REVISANDO EL CONJUNTO DE ARTE ESQUE- MÁTICO}

Contrasta la importancia de las manifestaciones esquemáticas de la Cova Tabac (Díez Coronel, 1985; Castells (dir.), 1990) y el actual deterior o en el que se encuentran, que forzó su restauración. En el marco de una investigación monográfica sobre el arte Esquemático del Prepirineo de Huesca y Lleida, P. Lanau (2019) propuso integrarlas en su estudio. A raíz de estos trabajos se identificaron dos nuevas figuras.

\subsection{Una nueva representación gráfica del panel de pinturas}

Las diferencias entre la representación que presentamos y los calcos anteriores son sustanciales, afectando a la disposición de las figuras. Además de la nueva documentación del panel pintado se ha realizado una nueva lectura de las grafías, más ajustada gracias al tratamiento digital de las imágenes. Este calco se presenta sobre el dintel en el que aparecen lo que permite visualizar el contexto en que se ubican las pinturas (Fig. 7a).

El panel se localiza a 39 metros de la entrada, si bien los motivos pintados se identifican con relativa facilidad al recibir iluminación indirecta que penetra por la boca de la cueva. Las pinturas están representadas sobre un dintel a través del que se accede al interior del karst, y a $5 \mathrm{~m}$ donde se excavaron las estructuras arqueológicas reseñadas. Se ubican a 2,4 m de altura, aunque el nivel del piso en esa zona está muy modificado. A lo largo 1,80 $\mathrm{m}$ se suceden 12 figuras posiblemente realizadas en un único evento que conforman una escena de difícil interpretación. Esta cuestión deberá abordarse en futuros estudios.

Los motivos realizados en tinta plana y con pigmentos rojizos comprenden varios antropomorfos, un esteliforme, un pectiniforme y diversos signos de difí-
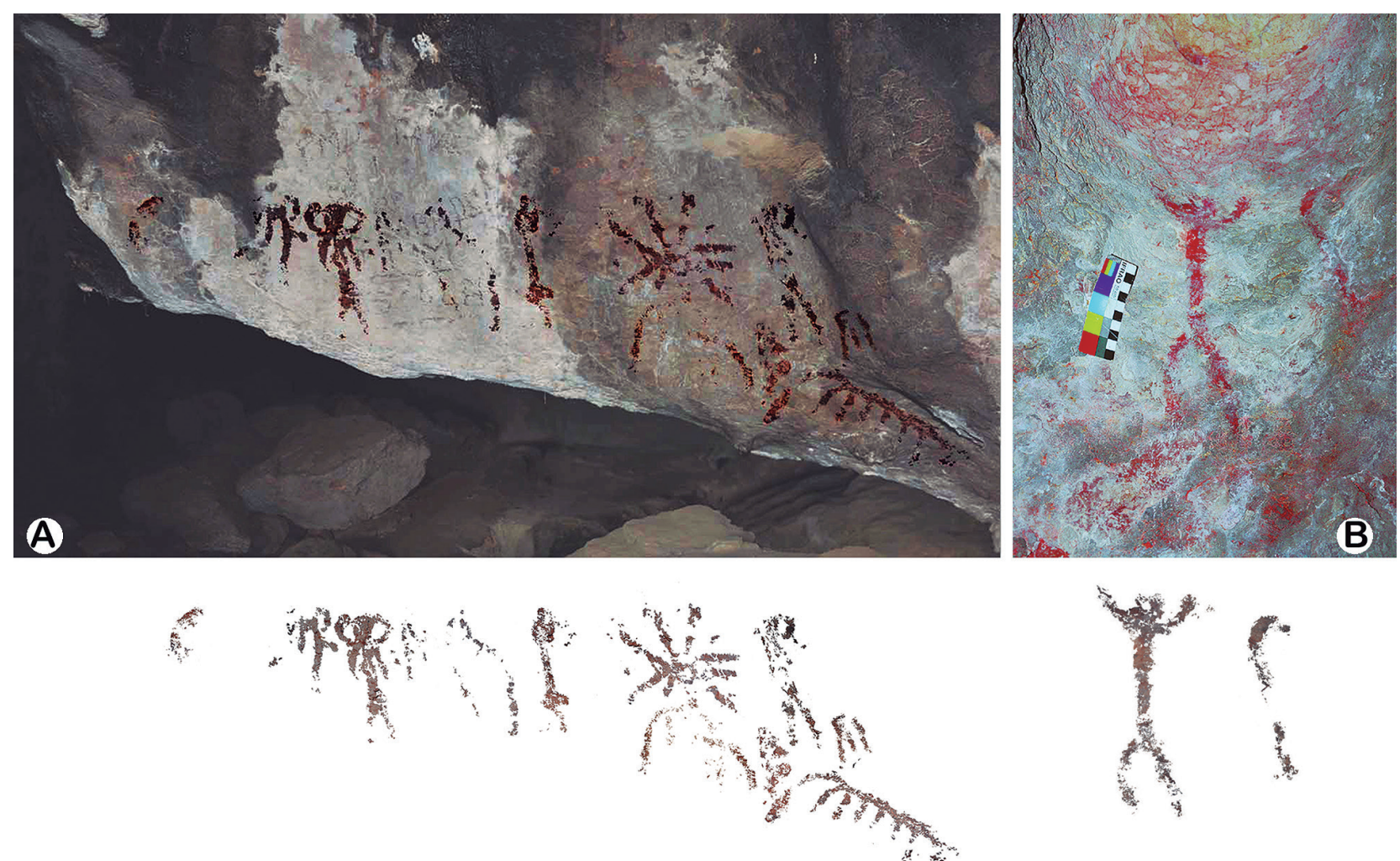

Fig.7. A) Reproducción del panel de figuras restituidas virtualmente sobre el dintel, en el que se reconocen los motivos pectiniforme y soliforme, y el antropomorfo "orante". B) Nuevas grafías localizadas en el interior de una chimenea adyacente con la representación del antropomorfo en "doble Y" y el signo curvado (imagen tratada con DStretch). En la parte inferior se visualizan los calcos de las figuras (Lanau, 2019). / A) Reproduction of the panel with schematic signs. B) New figures: "double Y" shape anthropomorph (image treated with DStretch). Bottom representation of the figures (Lanau, 2019). 
cil catalogación (Lanau, 2019). La figura emblemática y mejor conservada es el denominado "oculado" (Díez Coronel, 1985), un antropomorfo de $27 \mathrm{~cm}$ que a ambos lados de la cabeza conserva trazos en forma de asa que podrían representar los brazos elevados sobre la cabeza, o bien un tocado o peinado. Según A. Alonso este motivo remite a la esfera de los "orantes" del arte Esquemático del Neolítico antiguo (en Castells (dir.), 1990). Otros dos antropomorfos flanquean un círculo central de $20 \mathrm{~cm}$ de diámetro del que parten trazos radiados, catalogado como "soliforme". El mural se cierra -o se abre- en el extremo derecho con una línea horizontal de la que parten pequeños trazos verticales que se atribuyen a un motivo "pectiniforme".

\subsection{Las nuevas grafías}

Al revisar las paredes adyacentes, escondidas en el interior de una pequeña chimenea del techo de la cueva y sobre la vertical de las estructuras del grupo $B$ se descubrieron dos representaciones enfrentadas al panel. Estas grafías se corresponden con un antropomorfo de $30 \mathrm{~cm}$ formado por un trazo vertical con piernas en ángulo y brazos orientados hacia arriba; y un signo vertical curvado en forma de cayado, con el extremo superior curvado (Lanau, 2019) (Fig. 7b). Ambas composiciones sobre pigmento rojo se relacionan con los motivos del panel principal, destacando el antropomorfo en forma de "doble Y", elemento relevante en la iconografía del arte Esquemático Mediterráneo (Hernández, 2006; Lanau, 2019).

\section{DISCUSIÓN: LA POSICIÓN CRONOCULTURAL DE LA COVA DEL TABAC}

Pese a persistir un profundo desconocimiento sobre este enclave, se puede evaluar su integración dentro del contexto cronocultural del Prepirineo Oriental y proponer posibles relaciones entre el conjunto material y las representaciones artísticas.

\subsection{La unidad cultural del conjunto arqueológico de la Cova del Tabac}

Estos hallazgos confirman que la cavidad no está totalmente expoliada y algunos sectores preservan contextos arqueológicos. En las estructuras de los grupos A y B se recuperó un significativo conjunto de materiales. Estos indicadores señalan distintas actividades en un espacio que radiométricamente parece estar relacionado, cuestión que deberá evaluarse a partir del análisis pormenorizado del material arqueológico.

Estos artefactos y ecofactos refieren a la aparición del Neolítico en la zona. Aunque en el texto no se ha mencionado la recuperación de ecofactos, en la fracción orgánica del sedimento Natalia Alonso (Univ. de Lleida) identificó semillas de cereal -Triticum dicoccum y Triticum aestivium/durum- que se seleccionaron para datar
(Tabla 1). A su vez, caprinos y bovinos subrayan este nuevo tipo socio-organizativo basado en la agricultura y pastoreo. Habitualmente, la irrupción de este nuevo sistema se acompaña de un abrupto cambio a favor de los domesticados, que contrasta con la aparente abundancia de restos de ciervo. Aunque la presencia de animales domésticos es clave a la hora de identificar la aparición del Neolítico, esta observación deberá evaluarse a partir del estudio zooarqueológico ya que en varios sitios del norte de Iberia la caza de ungulados salvajes es un componente significativo (Altuna y Mariezkurrena, 2009). Tampoco puede descartarse que la presencia de ciervo en la Cova del Tabac tenga un significado especial, cuestión que deberá explorarse conjuntamente con el resto de evidencias recuperadas en este enclave.

La técnica de talla y los soportes laminares del instrumental lítico y ornamentos como los brazaletes de pectúnculo, remiten igualmente a este ámbito Neolítico. Paralelamente, la combinación de cerámicas decoradas con impresiones, incisiones, cordones se asignan al estilo impreso-inciso propio del Prepirineo e interior peninsular (Oms, 2017; Rojo et al. 2018; Laborda, 2019), tal y como se discute en el epígrafe 7.3.

Al explorar las similitudes entre las descripciones de LI. M. Vidal y los materiales señalados en este estudio, son interesantes las "piedras para moler colores" relacionadas con el machacado de minerales que Vidal (1894) vinculó con el uso de pintura corporal por las gentes de la cueva. El hallazgo de cantos con residuos y la recuperación de óxidos minerales en el actual proyecto, son elementos de convergencia entre las excavaciones antiguas y el registro actual. Estos artefactos se citan puntualmente en este período (Bea, 2014), excepto en el Neolítico antiguo de Chaves que se catalogaron 102 cantos tintados con ocre, 30 con grafías figurativas (Utrilla y Baldellou, 2001). En Cova del Tabac estos cantos que se relacionan con el pulverizado y tratamiento de ocre, sin que de momento se adviertan figuraciones, parecen desempeñar un papel esencial en las actividades de las gentes que usaron la cueva.

\subsection{Tiempo y espacio del arte Esquemático de la Cova del Tabac}

Establecer una cronología acotada para estas pinturas no resulta sencillo, al igual que cuando se analiza de forma individualizada cualquier panel adscrito a una de las tradiciones gráficas post-paleolíticas. Los motivos representados responden a temas simples y universales, siguiendo convenciones estilísticas sencillas con un amplio desarrollo geográfico y temporal lo que dificulta realizar precisiones cronoculturales. Su posible rango cronológico puede apoyarse a partir de su integración dentro de un marco general, y su asociación con un contexto arqueológico puede ser informativa (Lanau, 2019).

Se ha señalado que las grafías que caracterizan el fenómeno esquemático visualizan la aparición de 
los primeros agricultores-pastores (Hernández y Martí, 2000; Utrilla y Bea, 2009). Así mismo, los antropomorfos en "X", "Y", "doble Y" comunes en los paneles esquemáticos se relacionan con las decoraciones cerámicas del Neolítico cardial (Hernández, 2006; Martí et al., 2018). Los yacimientos del Prepirineo de Huesca aportan argumentos a este debate. El conjunto de cantos pintados de Chaves es singular al representar antropomorfos y soliformes propios del arte Esquemático y "orantes con dedos marcados y rayos en la cabeza" definitorios del arte Macroesquemático, lo que permite proponer que ambas tradiciones pudieron estar estrechamente vinculadas (Utrilla y Baldellou, 2001; Hernández, 2016). Igualmente, un soliforme localizado en el barranco de Solencio -a 200 m de Chaves- se adscribe a la esfera del Neolítico antiguo de este enclave. Por otro lado, entre los materiales de cronología diversa recuperados en la excavación a pie de los paneles esquemáticos de Remosillo y Huerto Raso se recuperaron cerámicas impresas atribuidas al Neolítico antiguo (Utrilla y Calvo, 1999).

El conjunto material recuperado en Cova del Tabac y representaciones como antropomorfos "orantes" se relacionan con momentos antiguos del Neolítico, y podrían indicar que el panel fue realizado en este período. Igualmente, destacar un paralelo cercano en el soliforme representado en una cerámica "Epicardial" de Cova Colomera (Oms et al., 2013). No obstante, estos temas tienen una amplia perduración temporal y con análogos en materiales de épocas posteriores. De hecho, estas pinturas fueron atribuidas a la edad del Bronce a raíz del hallazgo al pie del panel de un asa de apéndice de botón (Díez Coronel, 1985; Utrilla y Calvo, 1999). No se puede descartar que esta cavidad registrara ocupaciones de ese periodo, pero los materiales recuperados por LI. M. Vidal y los aquí expuestos son coherentes con la hipótesis que las grafías esquemáticas advertirían de la presencia de los primeros agropastores.

Algunos parámetros apuntan a que esta cueva sería un espacio social con fuerte carga simbólica. En vistas a evaluar esta posibilidad es preciso analizar la relación de este espacio con la subsistencia y las prácticas culturales de estas comunidades. Su ubicación en la cima de una de las crestas del desfiladero del Mont Roig en un paisaje emblemático que le confiere gran visibilidad se concatena con la proximidad a la confluencia de los ríos Noguera-Pallaresa y Segre (Fig. 1). Estos elementos paisajísticos propician la transformación de este entorno natural en un paisaje social. Los abrigos pintados suelen situarse en lugares a lo largo de las redes de comunicación importantes que facilitan la transmisión cultural y la ocupación simbólica de esos espacios. Pero estas localizaciones que combinan tierras aptas para la agricultura con acceso a pastos de montaña advierten que los abrigos pintados señalizan espacios intensamente gestionados por comunidades campesinas (Martínez García, 2018).

La situación de las pinturas en el interior de la cueva es excepcional respecto al conjunto de estaciones atribuidas al ciclo Esquemático (Lanau, 2019). Pese a localizarse a 40 metros de profundidad, las pinturas se sitúan en un friso visible e iluminado por la luz que penetra por la boca de la cavidad. Al mismo tiempo, su ubicación sobre un dintel que marca la transición entre la sala de entrada y la parte profunda y oscura de la cueva, es una singularidad que debería integrarse en la discusión del significado socio-simbólico de esas representaciones.

\subsection{El contexto cronocultural de la Cova del Tabac}

La serie radiométrica integra este conjunto material dentro del proceso neolitizante que registra la vertiente sur del Pirineo en el tercio final del VI milenio (53005000 cal BC). La combinación de motivos decorativos cerámicos compuestos por impresiones, incisiones, cordones, impresiones-incisiones, impresiones-cordones y puntualmente boquique, remite al estilo impreso-inciso del Neolítico antiguo señalado en el Prepirineo de Huesca entre otros en Chaves 1b, Olvena, Remosillo, Espluga de la Puyascada, Forcón, (Laborda, 2019), Trocs (Rojo et al., 2013); en las primeras sierras del Prepirineo de Lleida en Colomera y Parco (Oms, 2014), Xicotó (Oms et al., 2019), Cova Gran de Santa Linya (Mora et al., 2019) y Margineda, en el Pirineo Axial (Oms et al., 2016b). Algunas decoraciones cerámicas de la Cova Tabac tienen paralelos directos en las impresiones oblicuas sobre pasta fresca descritas en Olvena y Remosillo en el Prepirineo de Huesca (Laborda, 2019), o en las cerámicas impresas de la fase III de Valmayor XI, en el bajo Ebro (Rojo et al., 2015).

Este evento neolítico corresponde con un horizonte independiente que no circula por el litoral que eclosiona pocas centurias después del Neolítico cardial costero (Guilaine y Manen, 2007). Su desarrollo temporal seria contemporáneo a la fase II de la neolitización del Noreste de la Península Ibérica propuesta por Oms (2014), que tendría en los valles del Cinca-Segre una posible ruta de penetración tanto hacia el nordeste de Iberia como hacia el interior peninsular (Utrilla et al., 1998, Rojo et al., 2018). Este escenario permite proponer que hacia 5600-5400 cal BC en el Prepirineo se identifica una primera -y por el momento- discreta irrupción de poblaciones que podrían provenir de la costa reconocidas por las cerámicas con impresión cardial recuperadas en Chaves 1b y Forcas II (Laborda 2019) y Bofia de Valldan (Oms 2014). Pero es la generalización del estilo impreso-inciso, hacia 5300 cal BC, cuando se advierte de una intensa implantación del Neolítico en esta zona.

Els Aspres de la Noguera, en el contacto entre la Depresión del Ebro y las primeras sierras del Prepirineo es un paisaje kárstico propicio para la formación de abrigos y cuevas en las que se detectan ocupaciones adscritas al horizonte impreso-inciso señaladas en Cova Colomera, Cova del Parco, Xicotó, Cova Gran de Santa Linya, y Cova del Tabac (Mora et al., 2019). Po- 
siblemente dentro de esta esfera cronocultural podrían integrarse las diaclasas inhabitables de Coll de Porta y Forat de Conqueta que guardan grandes contenedores cerámicos destinados al almacenaje (González Marcén et al. (coord.), 2010). Por otro lado, en las excavaciones a principios del siglo pasado en Cova Joan d'Os, el Foric y Cova Negra de Tragó (Bosh Gimpera, 1923) y posteriormente adscritas al impreciso "círculo cultural de las cuevas" (Maluquer, 1945) se identifican materiales de factura similar (Oms, 2014). En paralelo, las paredes de la Cova dels Villars, la Diva, Cami de Vilaseca, la Covatxa del Pont del Congost o el grupo de Santa Ana preservan paneles gráficos de difícil adscripción temporal pero que temática y estilísticamente entroncan con el arte Esquemático del Prepirineo (Lanau, 2019). Estos indicadores posiblemente abarcan un dilatado arco temporal que advierte del impacto de este evento Neolítico en els Aspres de la Noguera, e indican que la Cova del Tabac podría desempeñar un papel singular en este proceso (Fig. 8).

\section{CONCLUSIONES Y PERSPECTIVAS DE FUTURO}

Cova del Tabac se integra en este evento de Neolítico antiguo que se resigue por las cuencas de los ríos Cinca-Segre y que a partir de $5300 \mathrm{cal} B C$ se registra en más de 20 cuevas y abrigos, siendo el estilo decorativo impreso-inciso un icono principal (Oms, 2014; Laborda 2019). En fechas similares este evento se rastrea por el interior de Iberia (Rojo et al. 2018). Es decir, su impacto no se circunscribe a los valles del Prepirineo y será necesario evaluar su papel en la consolidación del Neolítico por la Península Iberia en el último tercio del VI milenio BC. Es interesante la baja intensidad de la fase Cardial que irrumpe en algunos sitios del Prepirineo de Huesca, pero que se focaliza en la franja litoral (Garcia Puchol et al., 2018).

En els Aspres de la Noguera este desarrollo se visibiliza en abrigos y cuevas, algunas de difícil acceso, otras inhabitables, que a una escala regional desempeñan distintas funciones aunque sus implicaciones organizativas no son evidentes. Sin embargo, su ubicación adyacente a grandes valles y vías fluviales al pie de montañas, definen un biotopo que permite combinar la agricultura cerealista con el pastoreo transtermitente (Fig. 8).

Dentro de esta caracterización, Cova del Tabac podría desmarcarse de esta perspectiva estrictamente "subsistencial" (Fig. 1). Aunque el expolio que ha sufrido dificulta reconstruir que actividades se realizaron, el hallazgo de varias fosas y un hogar en una zona poco iluminada, consignan varias singularidades que merecen subrayarse. La primera, por qué en una esfe-

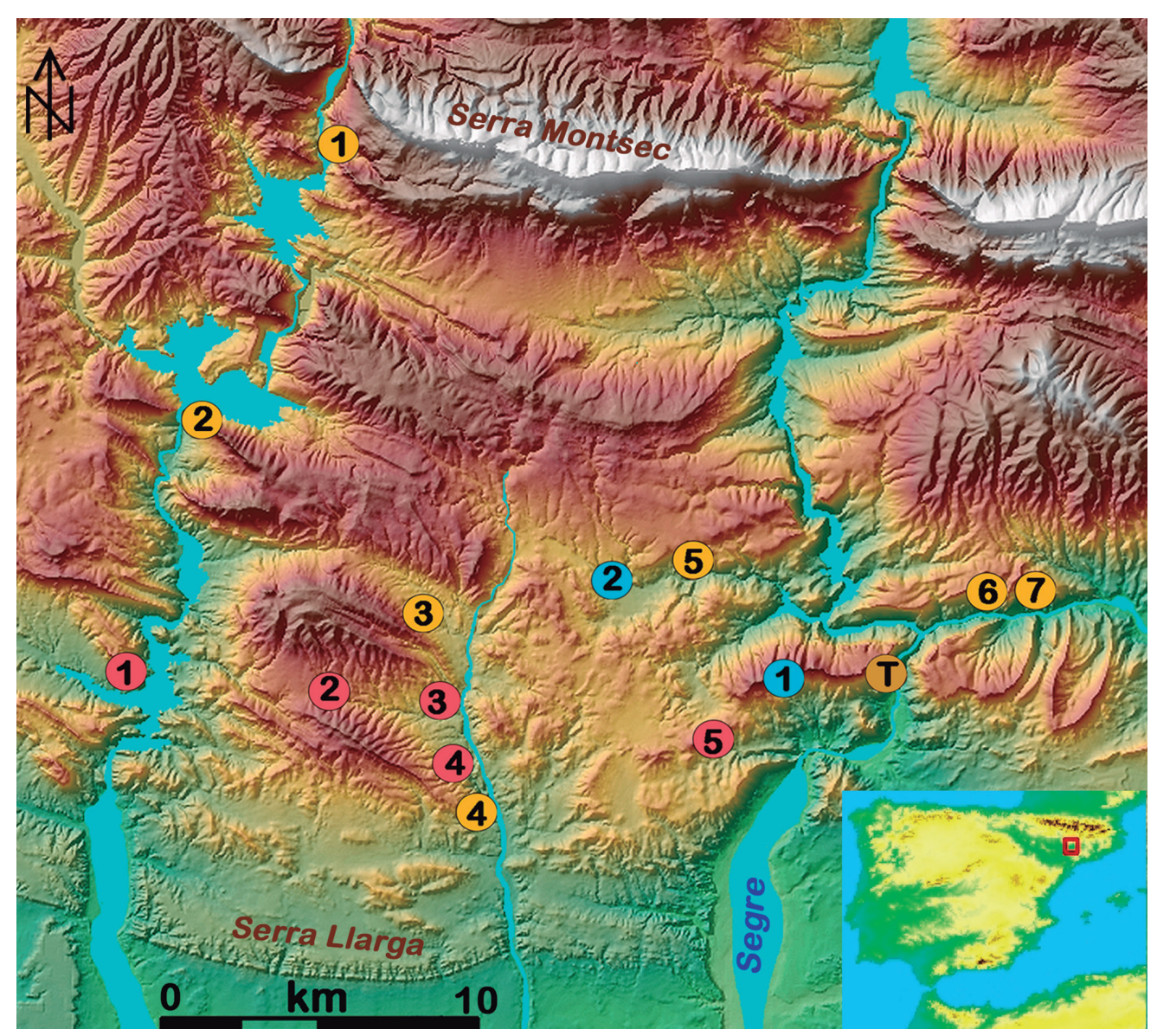

Fig.8. Yacimientos adscritos al Neolítico antiguo en els Aspres de la Noguera. En amarillo cuevas y abrigos: 1) Cova Colomera, 2) Cova Negra de Tragó, 3) Cova d'en Joan d'Os, 4) Cova del Foric, 5) Cova Gran de Santa Linya, 6) Abric del Xicotó, 7) Cova d'en Parco. En azul las diaclasas-almacén: 1) Coll de Porta, 2) Forat de Conqueta. En rojo localizaciones con arte esquemático: 1) Area del pantano de Santa Ana, 2) Corral Camí de Vilaseca, 3) Cova Pont del Congost, 4) Cova dels Vilars, 5) Abric de la Diva. T: Cova del: Tabac. / Early Neolithic sites at els Aspres de la Noguera. Yellow caves and rock-shelter: 1) Cova Colomera, 2) Cova Negra de Tragó, 3) Cova d'en Joan d'Os, 4) Cova del Foric, 5) Cova Gran de Santa Linya, 6) Abric del Xicotó, 7) Cova d'en Parco. Blue storage-caves: 1) Coll de Porta, 2) Forat de Conqueta. Red Squematic rock Art: 1) Santa Ana dam, 2) Corral Camí de Vilaseca, 3) Cova Pont del Congost, 4) Cova dels Vilars, 5) Abric de la Diva. T: Cova del Tabac. 
ra organizativa en el que los animales domésticos son prioritarios, el ciervo parece tener un papel destacado. Otro elemento son los indicadores relacionados con el tratamiento del ocre. Finalmente, las representaciones esquemáticas, motivos simples y con fuerte carga simbólica, podrían vincularse con la irrupción de los primeros agricultores y pastores en estos valles.

Relacionar este conjunto de pinturas con el registro material es una hipótesis que deberá ser abordada. Sin embargo, es tentador proponer que esos artefactos son el reflejo de acciones realizadas en un espacio destinado al desarrollo de prácticas comunitarias e identitarias de esos grupos. Sin duda, este es uno de los diversos interrogantes planteados en este artículo que merecerán futuras reflexiones, y constituye incentivo para investigar este evento del Neolítico antiguo en els Aspres de la Noguera.

\section{AGRADECIMIENTOS}

Josep Castells catalizó las sinergias entre el Ajuntament de Camarasa (Lleida) y el Servei d'Arqueologia i Paleontologia que encauzó la conservación de este emblemático lugar. Esta acción se integra en los proyectos PREHISTOPIRINEO (PID2019-104843GB-I00), Asentament Humà al Plistocé final i Holocé del sudest dels Pirineus del Servei d'Arqueologia i Paleontologia-Generalitat de Catalunya y del Grup de Reçerca 2017SGR-1357. Cova del Tabac forma parte del Origens-Geoparq Mundial UNESCO.

\section{BIBLIOGRAFÍA}

Altuna, J., Mariezkurrena, K., 2009. Tipos de cabañas ganaderas durante el Neolítico del País Vasco y zonas próximas. Archaeofauna 18, 137-157.

Bea, M., 2014. Elementos líticos pulimentados y cantos con ocre de los abrigos de Forcas I y II". En: Utrilla, P, Mazo, C. (Eds.), La Peña de Las Forcas, 227-236. Monografías Arqueológicas 46. Zaragoza.

Binder, D., Perlès, C., Inizan, M. L., Lechevallier, M., 1990. Stratégies de gestion des outillages lithiques au Néolithique. Paleo 2, 257-283.

Bosch Gimpera, P., 1923. Resultats de l'exploració de coves de Catalunya". Anuari de l'Institut d'Estudis Catalans MCMXV-XX, 473-476.

Bronk Ramsey C., 2020. https://c14.arch.ox.ac.uk/oxcal

Castells, J. (dir.), 1990. Corpus de pintures rupestres de Catalunya. Vol. 1. La Conca del Segre. Dpt. de Cultura. Generalitat de Catalunya, Barcelona.

De la Vega, J., 1981. Aplec de documents arqueològics de les coves del Montsec. Mediterrània 12

Díez-Coronel, L., 1985. Pinturas rupestres esquemáticas en la Cova del Tabac, en Camarasa (Lérida). XVII Congreso Nacional de Arqueología-1983, 161-170. Logroño.

García Puchol, O., Díez Castillo, A., Pardo-Gordó, S., 2018. New insights into the neolithisation process in southwest Europe according to spatial density analysis from calibrated radiocarbon dates. Archaeol Anthropol Sci 10, 1807-1820.
González-Marcén, P., Mora,, R., Roda, X. (eds.), 2010. Forat de Conqueta. Treballs d'Arqueologia 16-17. http://ddd.uab. cat/record/49? ln=ca

Guilaine, J., Manen, C., 2007. From Mesolithic to Early Neolithic in Western Mediterranean. Proceedings of the British Academy 144, 21-51.

Hernández, M. S., Martí Oliver, B., 2000-2001. El arte rupestre de la fachada mediterránea: entre la tradición Epipaleolítica y la expansión Neolítica. Zephyrus 53, 241-265.

Hernández, M.S., 2006. Arte esquemático en la fachada oriental de la Península Ibérica. 25 años después Zephyrus 59, 199-214.

Hernández, M.S., 2016. Arte Macroesquemático vs. Arte Esquemático. Reflexiones en torno a una relación intuida. Trabajos Varios SIP 119, 481-490.

Laborda, R., 2019. El Neolítico antiguo en el Valle medio del Ebro. Una visión desde la cerámica y las dataciones radiocarbónicas. Monografías Arqueológicas 55. Zaragoza.

Lanau, P., 2019. La Pintura Esquemática en las Sierras Exteriores Pirenaicas. Tesis Doctoral inédita. Universidad de Zaragoza.

Maluquer, J., 1945. La provincia de Lérida durante el Eneolítico, Bronce y Primera Edad del Hierro. Ilerda V, 173-245.

Martí Oliver, B., Juan Cabanilles, J., García Borja, P., 2018. Las decoraciones figurativas y simbólicas de las cerámicas del Neolítico Antiguo en las comarcas meridionales valencianas. In: Soler, Pérez, R., Barciela V. (Eds.), Rupestre. Los Primeros Santuarios, 108-125.

Martínez García, J., 2018. Artes esquemáticos de las sociedades ágrafas en la Prehistoria reciente Ibérica. In: Soler, Pérez, R., Barciela V. (Eds.), Rupestre. Los Primeros Santuarios, 152-163.

Mora, R., Martínez-Moreno, J., Roy, M., González-Marcén, P., Roda, X., Vega, S., Pizarro, J., Benito-Calvo, A., 2019. Dels neandertals als primers camperols: un recorregut pel poblament prehistòric dels Aspres de la Noguera. Tribuna d'Arqueologia 2016-2017, 11-28.

Oms, X., Pedro, M., Morales, J.I., Allué, E., Frigola, J., Mendiela, S., Rodríguez Cintas, A., Serra, J., Yubero, M., 2013. Cova Colomera 30 anys després. Ocupacions humanes entre 6180$3280 \mathrm{BP}$ al Congost de Mont-rebei. Primeres Jornades d'Arqueologia i Paleontologia del Pirineu-Aran, 116-123.

Oms, X., 2014. La Neolitització del Nord-Est de la Península Ibèrica a partir de les datacions de ${ }^{14} \mathrm{C}$ i les primeres ceràmiques impreses c.5600-4900 cal BC. Tesis Doctoral. Universidad de Barcelona. http://hdl.handle.net/2445/69672

Oms, X., Martín, A., Esteve, X., Mestres, J., Morell, B., Subirà, M., Gibaja, J., 2016a. The Neolithic in Northeast Iberia: Chronocultural phases and ${ }^{14} \mathrm{C}$. Radiocarbon 58, 291-309.

Oms, X., Gibaja, J. F., Mazzucco, N., Guilaine, J., 2016b. Revisión radiocarbónica y cronocultural del Neolítico antiguo de la Balma Margineda. Trabajos de Prehistoria 73, 29-46.

Oms, X., Sánchez de La Torre, M., Petit, M.A. López-Cachero, F.J., Mangado, X. 2019. Nuevos datos del VI y V milenio cal BC en el llano y Prepirineo de Lleida: el Abric del Xicotó y Les Auvelles. Munibe Antropologia-Arkeologia 70, 93-107.

Ortega, D., Roqué, C., Ibáñez, J., Beamud, E., Larrasoaña, J., Sáez, A., Terradas, X., 2018. The chert from the Castelltallat Formation (south-central Pyrenees): archaeometric characterisation and archaeological implications. Archaeological and Anthropological Sciences 10(6), 1329-1346. 
Roda Gilabert, X., Martínez-Moreno, J., Mora, R., 2016. Ground stone tools and spatial organization at the Mesolithic site of Font del Ros. Journal of Archaeological Science: Reports 5, 209-224.

Rojo, M., Peña-Chocarro, L., Royo, J.I., Tejedor, C., García-Martínez De Lagrán, I., Arcusa, H., Garrido-Pena, R., Moreno, M., Mazzuco, N., Kromery B., W. Alt. K., 2013. Pastores trashumantes del Neolítico antiguo en un entorno de alta montaña: secuencia cronocultural de la Cova de Els Trocs. BSAA Arqueología 79, 9-55.

Rojo, M., Tejedor, C., Peña-Chocarro, L., Royo Guillén, J., García Martínez de Lagrán, I., Arcusa, H., San Millán, Mª., Garrido, R., Gibaja, J., Mazzuco, N., Clemente, I., Mozota, M., Terradas, X., Moreno, M., Pérez, G., Álvarez-Fernández, E., Jiménez, I, Gómez Lecumberri, F., 2015. Releyendo el fenómeno de la neolitización en el Bajo Aragón a la luz de la excavación del cingle de Valmayor XI. Zephyrus 75, 37-66.

Rojo, M., García-Martínez de Lagrán, I., Royo-Guillén, J., 2018. The beginning of the Neolithic in the mid-Ebro valley and in Iberia's Inland Spain. Quaternary International 470, 398-438.

Roy, M., Tarriño, A., Benito-Calvo, A., Mora, R., Martínez-Moreno, J., 2013. Aprovisionamiento de sílex en el Prepirineo oriental durante el Paleolítico superior antiguo: el nivel arqueológico 497C de Cova Gran de Santa Linya. Trabajos de Prehistoria 70, 7-27.

Roy, M., Mora, R., Plasencia F., Martínez-Moreno, J., Benito-Calvo, A., 2017. Quartzite selection in fluvial deposits: The N12 level of Roca dels Bous. Quaternary International 435, 49-60.
Serra-Ràfols, J., 1921. La Col·lecció Prehistòrica Lluís Marian Vidal. Materials de Prehistòria Catalana I. Seminari de Prehistòria de la Universitat de Barcelona.

Utrilla, P., Cava, A., Alday, A., Baldellou, V., Barandiarán, I., Mazo, C., Montes, L., 1998. Le passage du Mésolithique auv Néolithique ancien dans le Bassin de l'Ebre (Espagne) d'apres les datations C14. Préhistoire Européenne 12, 171-194.

Utrilla, P., Calvo, M. J., 1999. Cultura material y arte rupestre «levantino»: la aportación de los yacimientos aragoneses a la cuestión cronológica. Una revisión del tema en el año 2000. Bolskan 16, 39-70.

Utrilla, P., Baldellou, V., 2001. Cantos pintados neolíticos de la cueva de Chaves (Bastarás, Huesca). Salduie 2, 45-125.

Utrilla, P., Bea, M., 2009. Acerca del arte Esquemático. En: Aragón. Cruz, R., Ferrer, E. (Eds), Estudios de Prehistoria y Arqueología. Homenaje a Pilar Acosta, 109-140.

Vega, S., Pinto, L., Mora, R., González, P., Laborda, R., Benito Calvo, A., Martinez Moreno, J., 2020. Construint la Cova del Tabac del secle XXI. Muntanya 932, 54-65.

Vidal, L. M., 1894. Coves prehistoriques de la provincia de Lleyda. Butlletí del Centre Excursionista de Catalunya 13, 1-31. 
